\title{
MATHEMATICAL DESCRIPTION OF TRACTOR SLIPPAGE WITH VARIABLE TIRE INFLATION PRESSURE
}

\author{
Algirdas Janulevicius, Gediminas Pupinis, Antanas Juostas \\ Aleksandras Stulginskis University, Lithuania \\ algirdas.janulevicius@asu.lt, gediminas.pupinis@asu.lt, antanas.juostas@kesko.lt
}

\begin{abstract}
Tractor slippage is one of the main economic and environmental indicators for composing of tractor units. It is a key indicator showing the rational interaction of the tire to the road (soil) surface. If it is too big or too small, big energy losses occur. Slippage depends not only on the vertical loads to the driving wheels, but also on the wheel and soil grip area. The grip area between the wheel and soil usually increases by reducing the tire's air pressure. For the operation of tractor units (especially in agriculture) the preliminary calculation of the slippage, i.e. forecasting of the energy and economic task, is one of the most important. Tractor slippage prediction in most cases is calculated based on the traction coefficients. However, the coefficients mathematical expression does not include indicators that evaluate tire pressure in the tire. From the mathematical point of view, for the ability to optimize the slippage of the driving wheels, while at the same time seeking better ecological and economic performance, it is not enough to evaluate the traction coefficient dependencies on the traction forces and the vertical load of tires, but also dependencies on the tire performance indicators, too. This article will present a mathematical model that allows estimating the slippage of driving wheels at various air pressure in the tractor tires. Based on the experimental tractor slippage dependences on the traction power and air pressure in the tires and the calculations based on the empirical formula, the formulas for calculation of the limiting traction power and the degree of the coefficient of the mathematical model of the towing calculation were made. An expanded calculation method allows to calculate the slippage value of the tractor driven wheel for any permitted tire inflation pressure.
\end{abstract}

Keywords: farm tractor, draw pull, inflation pressure, slippage, traction coefficient.

\section{Introduction}

The main purpose of farm tractors is to perform drawbar work. This is defined by draw pull force and run speed. Draw pull and drive wheel slippage are the key indicators affected by interaction between the wheel and the soil surface [1]. Most scientific information sources show that about $20-55 \%$ of the available tractor power is wasted at the tire-soil interface, i.e. because of the drive wheel slippage and tire and soil deformation [2-4]. This energy consumes the tires and compacts the soil to a degree that may be detrimental to crop production. Efficient work of agricultural tractors includes: choosing an optimum work speed for a given tractor-implement unit; maximizing the tractive advantage of the traction devices, and minimizing the drive wheel slippage [5;6]. Among these, minimizing of the fuel consumption could be done with little efforts.

The agricultural tractors work at maximum efficiency, if their slippage is maintained in a certain rational range $[7 ; 8]$. As per the previous studies, it is recommended that farm tractors and drive wheels should be maintained to rational slippage at $10-15 \%$ to get better tractive performance and less slippage as this results in the expenses of too much fuel consumption to move the wheels, whereas too much slippage (greater than $15 \%$ ) can result in excessive tire turn and power loss through the tire, which is non-productive [9-11]. Most of the scientists have an opinion that agricultural tractors working in soil are most efficient, when the drive wheel slippage is in the range of 8-12\% $[5 ; 9 ; 12]$. Also it was determined that the tractive power increases according to the increase of slippage. The biggest tractive power, during field application, the tractor reaches at slippage of 10-20\% [12-13]. However, due to the adverse effect on the soil, wheeled tractors must not exceed the slippage more than $15 \%$ [12]. Therefore, when assembling the tractor units, it is necessary to consider not only the traction characteristics, but also the recommended value of the slippage. For example, the rational slippage value during ploughing application is about $8-12 \%$. The tire air pressure is playing big role on the driving wheel grip with the soil and slippage. For the agricultural tractor wheel slippage forecasting purpose, the tractive power and traction coefficient values are used [14; 15]. However, the proposed mathematical methods are not adapted for numerical evaluation of the tire inflation pressure. For the calculation of the optimal tractor wheel slippage it is important to know the attraction factor dependence on the size of the traction power and the vertical load on the tires, as well as the tire pressure indicators. The goal of this study is to investigate the tire air pressure influence on the tractor wheel slippage, tractive power and the traction coefficient. As well, according to the research results 
data, to provide the wheel slippage forecasting methodology based on the numerical evaluation of the tire inflation pressure.

\section{Materials and methods}

An important task for combining the tractor units is the preliminary calculation of the slippage, i.e. forecasting of the slippage. The forecasting of the tractor wheel slippage is based on evolving the traction power or traction coefficient [16; 17]. Fig. 1 shows the speed, forces, and wheel torque that are normally measured on a tractor during tractive performance tests. In the working condition $T_{f}$ and $T_{r}$ are the input torques, $F_{T}$ is the draw pull or net tractive force developed by the tractor, $W$ is the vertical applied load on the wheels and $R_{f}$ and $R_{r}$ the vertical ground reactions. In the free rolling condition $T_{f}$ and $T_{r}$ are zero and $F_{G f}$ and $F_{G r}$ become $F_{R f}$ and $F_{R r}$, the motion resistance force, and act in the opposite direction [17].

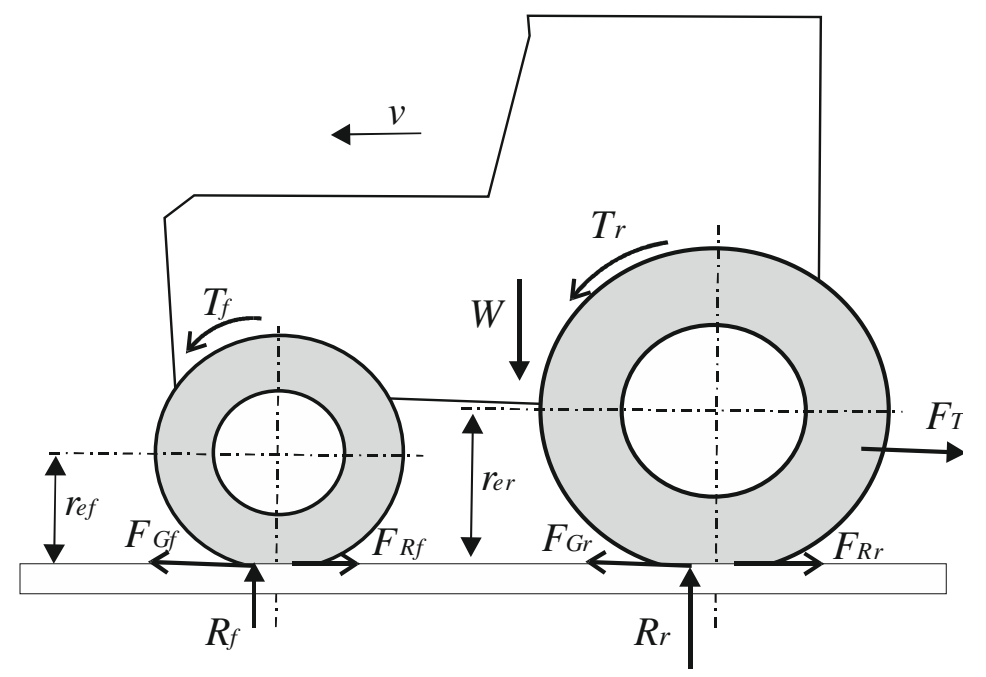

Fig. 1. Speed and forces measured on tractor during traction testing

The tractor forces are normally converted to a non-dimensional form by dividing by the vertical load $W$ of the tractor on the tires as follows.

- net traction coefficient of the tractor

$$
F_{T} / W=c_{T}
$$

- gross traction or torque coefficient

$$
F_{G} / W=c_{G}
$$

- total motion resistance coefficient of the tractor

$$
F_{R} / W=c_{R} .
$$

Slippage $s$ of the tractor is defined as follows:

$$
s=\frac{\omega_{r} r_{e r}-v}{\omega_{r} r_{e r}} \text { or } s=\frac{\omega_{f} r_{e f}-v}{\omega_{f} r_{e f}},
$$

where $\omega_{r}$ and $\omega_{f}-$ angular velocity of the rear and front wheels;

$v$ - forward speed of the tractor;

$r_{e r}$ and $r_{e f}$-effective radiuses of the rear and front wheels.

In the present paper, conventional Brixius model is basically used, which can deal with various kinds of soil types [18]. Research by Kim and Lee [17] in this model changed into a function of wheel slippage coefficient $s$ and soil reaction index $k$ in order to make calculus. Fig. 1 shows co-operating forces with the soil surface acting on a driving wheel by the wheel torque $T_{r}, T_{f}$ and vertical load $W$. In equation 5 , the drawbar pull $F_{T}$ is expressed by the difference of the total gross traction $F_{G}$ and total motion resistance $F_{R}$. 


$$
F_{T}=F_{G}-F_{R} .
$$

The gross traction $F_{G}$, and total motion resistance $F_{R}$ of the tractor are defined as follows [18]:

$$
\begin{gathered}
F_{G}= \pm W\left[C_{1}\left(1-e^{-C_{2} k}\right)\left(1-e^{\mp C_{3} s}\right)+\left(C_{4}\right)\right], \\
F_{R}=W\left(\frac{C_{5}}{k}+C_{4} \pm \frac{C_{6} s}{\sqrt{k}}\right),
\end{gathered}
$$

By equations 5, 6 and 7 the drawbar pull $F_{T}$ can be defined as:

$$
F_{G}= \pm W\left[C_{1}\left(1-e^{-C_{2} k}\right)\left(1-e^{\mp C_{3} s}\right)-\left(\frac{C_{5}}{k}+C_{4} \pm \frac{C_{6} s}{\sqrt{k}}\right)\right],
$$

where $C_{1} ; C_{2} ; C_{3} ; C_{4} ; C_{5}$ and $C_{6}$ are Brixius constants and the values can be determined by a non-linear regression technique.

For tractor traction tests, the driven wheel slippage is calculated from the experimental data in accordance to formula 4. Russian scientists Ginzburg, Parfionov and Shved have proposed an empirical formula for predicting tractor slippage [19]:

$$
s=s_{\lim }\left[1-\left(1-\frac{F_{T}}{F_{T}^{\lim }}\right)^{b}\right],
$$

where $\quad F_{T}^{\lim }$ - maximum traction power at limited slippage;

$s_{\text {lim }}-$ limited slippage (it is slippage, where at respective point it grows to full slippage, with almost no traction power);

$b$ - indicator of the function grade.

In order to combine the tractor slippage forecasting formula (9) with the tire inflation pressure values, an analysis of the experimental data of the slippage dependence on traction power at various tire pressures was performed. An analogous analysis was carried out to determine the tractor's slippage dependence on the traction coefficient.

For slippage dependency on drawbar pull tests at different inflation pressures in the tires, the tractor "Case Farmall 115U" was used. Tractor drawbar pull was performed by pulling tractors "Zetor 10540" and "MTZ 82", which were connected on rigid link. There was fitted a drawbar pull measurement sensor. The main technical data of the tractors used in the experiments are shown in Table 1. Dry stubble was selected (hardness in $5 \mathrm{~cm}$ depth was $0.40 \mathrm{MPa}$, soil moisture in $5 \mathrm{~cm}$ depth was $14 \%$ ) for investigations. The investigations were performed with turn off front driving wheels and blocked rear axle differential. The tests were carried out with the same air pressures in the front and rear tires, respectively, at pressures of $80,120,140,160,200,240 \mathrm{kPa}$.

Table 1

Tecnical data of tractors

\begin{tabular}{|c|c|c|c|}
\hline Parameter & Case Farmall 115U & Zetor 10540 & MTZ 82 \\
\hline Rated engine power, $\mathrm{kW}$ & 83 & 78.3 & 58.82 \\
\hline Weight of the tractor, $\mathrm{kg}$ & 4250 & 4336 & 3420 \\
\hline Wheelbase, mm & 2350 & 2380 & 2450 \\
\hline Front tires & $\begin{array}{c}\text { Michelin Multibib } \\
340 / 65 \mathrm{R} 24\end{array}$ & $16.9-14 \mathrm{R} 38$ & $16.9 \mathrm{R} 38$ \\
\hline Rear tires & $\begin{array}{c}\text { Michelin Multibib } \\
540 / 65 \mathrm{R} 34\end{array}$ & $12.4-28 \mathrm{TZ} 19$ & $15.5 \mathrm{R} 30$ \\
\hline Weight of the front axle, $\mathrm{kg}$ & 1990 & 1848 & 1221 \\
\hline Weight of the rear axle, $\mathrm{kg}$ & 2260 & 2488 & 2449 \\
\hline
\end{tabular}




\section{Results and discussion}

Figure 2 shows the traction power of the tested tractor under 240, 200, 160, 140, 120 and $80 \mathrm{kPa}$ of air pressure in the tires. The tests were carried out with an engaged tractor front axle and locked differentials.

As shown in Fig. 2 the tractor's slippage decreases while reducing the tire pressure. In the case of traction power less than $15 \mathrm{kN}$, tractor slippage was low at all tested tire inflation pressures and varied in a range of 4-7\%. At higher tractor loads, the tire pressures had a much greater impact on slippage. With a traction power of $20 \mathrm{kN}$, the tractor slippage was about $17 \%$, when the air pressure in the driven wheels was $240 \mathrm{kPa}$ and about $7 \%$ of slippage - when the tire pressure was $80 \mathrm{kPa}$. By increasing the traction power to $22.5 \mathrm{kN}$, the wheel slippage increased to $26 \%$ at the tire pressure of $240 \mathrm{kPa}$ and up to $9 \%$ of slippage was reached, when the tire pressure was $80 \mathrm{kPa}$. From Figure 2 it can be seen that when the tire pressure decreased from $240 \mathrm{kPa}$ to $80 \mathrm{kPa}$ the traction power of the tractor has increased in average for about $5 \mathrm{kN}$, while maintaining the driven wheel slippage at set value. Similar results were shown in previous own publications and other researchers' scientific works $[2 ; 15 ; 20-22]$.

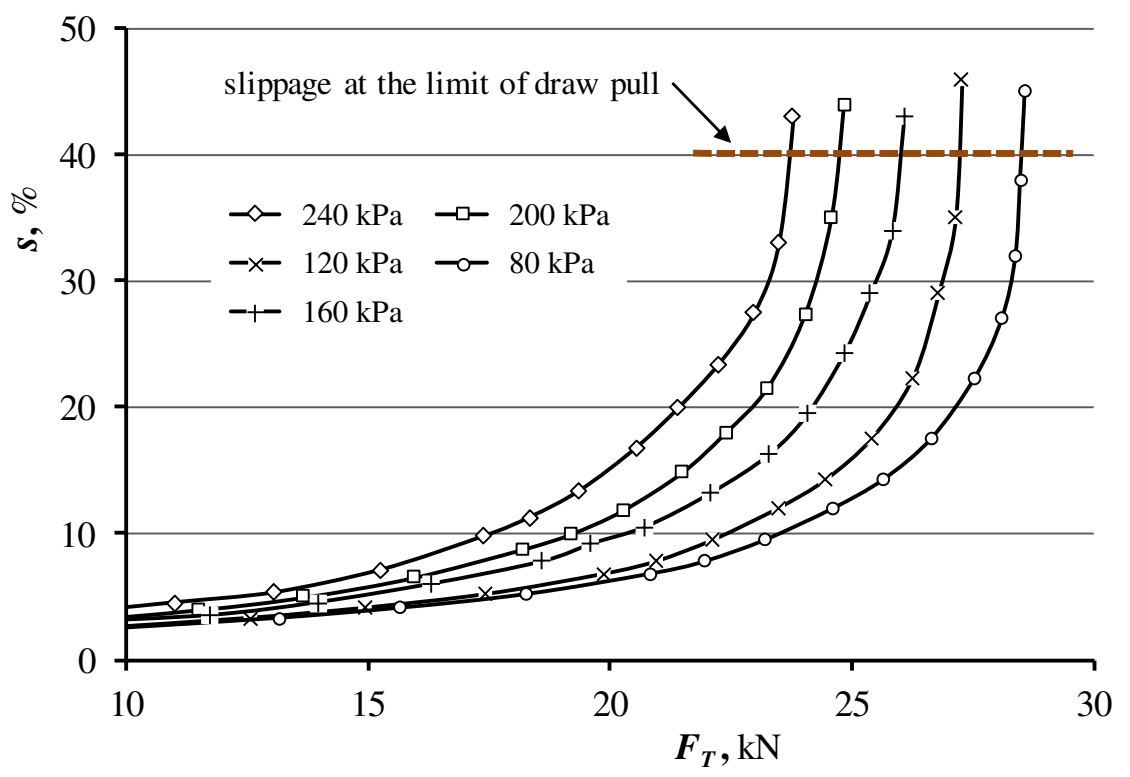

Fig. 2. Tractor slippage $s$ dependence on traction power $\boldsymbol{F}_{t}$ and tire inflation pressure $p$ in stubble

According to the data presented in Figure 2, the nominal (maximum) traction power $F_{T(\mathrm{im})}$ dependence on the tire inflation pressure was calculated. When the traction power reaches its nominal value (maximum), the tractor slippage increases to its full slip at almost not increased traction power. The nominal traction power $F_{T(\mathrm{lim})}$ dependence on the tire pressure $p$ is shown in Figure 3 . The figure shows that nominal traction power depends on the air pressure in the tires and has linear dependence.

According to the dependence (Fig. 3), a mathematical equation (10) was developed to calculate the nominal traction power at any given value of tire air pressures, when the nominal values of these sizes are known.

$$
F_{t \text { max }}=F_{v \text { max }}+a p_{v}-a p,
$$

where $F_{v \max }-$ maximum tractor traction power at nominal tire inflation pressure;

$p_{v}$ - nominal tire inflation pressure; $a$ is the coefficient of the function.

The coefficient of the function $a$ of the tested tractor was 0.0293 .

Based on the data presented in Figures 2 and 3, and the results of the calculations according to the formula (9), the tractor slippage mathematical function grade indicator $b$ dependence on the tire inflation pressure $p$ graph (Fig. 4) were calculated. 


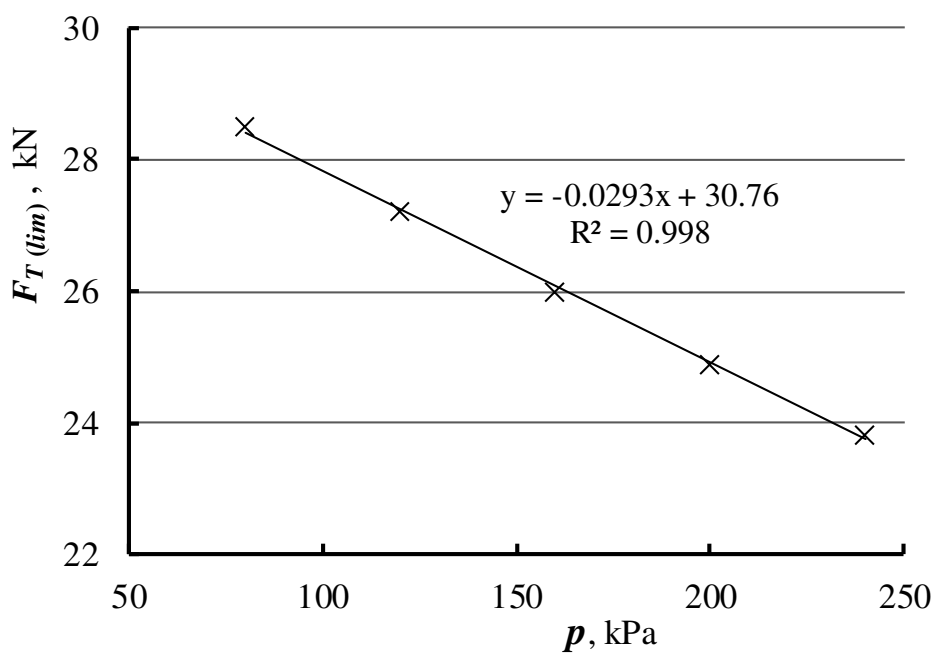

Fig. 3. Tractor limited traction power $\boldsymbol{F}_{T(\text { (im) }}$ dependence on tire inflation pressure $p$

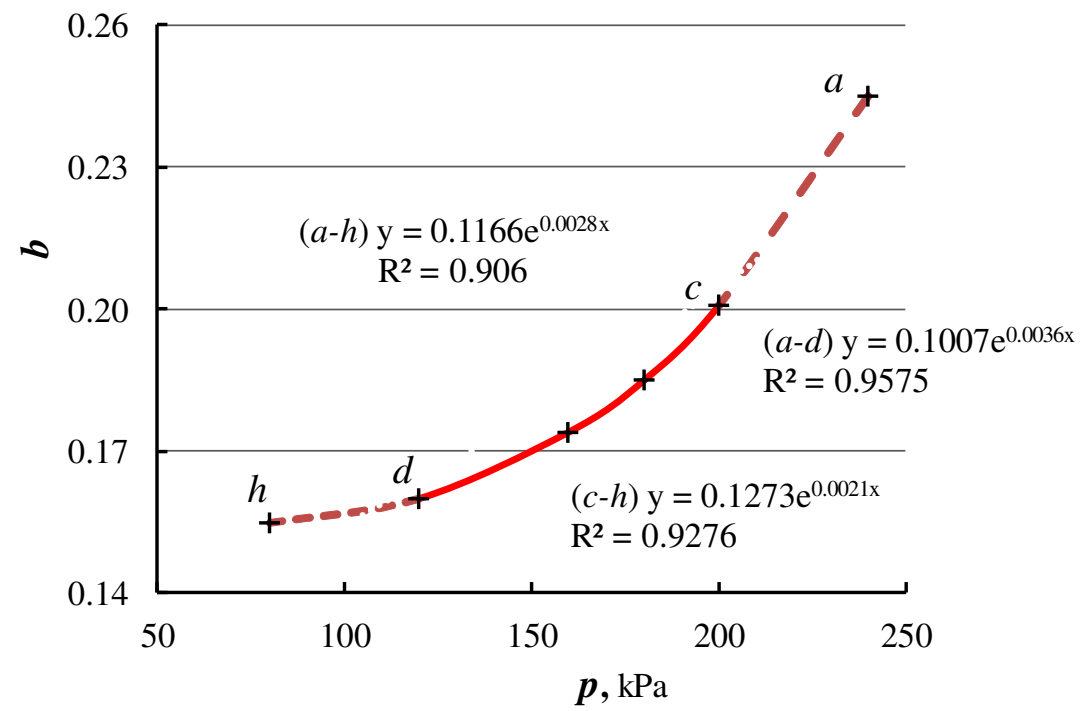

Fig. 4. Tractor slippage mathematical function grade indicator $b$ dependence on tire inflation pressure $p$ value

The analysis of the dependence (Fig. 4) shows sufficiently good $R^{2}$ values, when the curve was approximated in parts. The maximum value $\left(R^{2}=0.9575\right)$ shown for the curve section $a-d$, taking into account that used tire pressure limits during the tests are between 80-200 $\mathrm{kPa}$. Based on the dependence (Fig. 4), a mathematical equation (11) was developed. According to tractor slippage calculation formula (9), the grade of $b$ values at any permitted air tire inflation values, when the nominal values of these are known, can be calculated.

$$
b=b_{v} e^{\left(j p-j p_{v}\right)},
$$

where $b_{v}$ - slippage calculation mathematical function grade indicator $b$ value, at nominal tire inflation pressure;

$p_{v}$ - nominal tire pressure;

$j-$ the coefficient of the function.

The coefficient of the function $j$ of the tested tractor at tested conditions and at the tire inflation pressure $80-200 \mathrm{kPa}$ was 0.0036 . 


\section{Conclusions}

1. The study has shown that known mathematical methods for forecasting the wheel slippage are not suitable for numerical evaluation of the tire inflation pressure.

2. Based on the experimental tractor slippage dependences on the traction power and air pressure in the tires and the calculations based on the empirical formula (9), the formulas for the calculation of the limiting traction power $F_{T}^{\lim }$ and the degree of the coefficient $\mathrm{b}$ of the mathematical model of the towing calculation (Formula 9) were made. An expanded calculation method allows to calculate the slippage value of the tractor driven wheel for any permitted tire inflation pressure.

3. For further studies, this method, based on the numerical evaluation of the tire inflation pressure, could be expanded for tractor wheel slippage forecasting by including the traction coefficient.

\section{References}

[1] Osinenko P.V., Geissler M., Herlitzius T. A method of optimal traction control for farm tractors with feedback of drive torque. Biosystems engineering, 129, 2015, pp. 20-33.

[2] Ashok Kumar A., Tewari V.K., Gupta C., Pareek C.M. A device to measure wheel slip to improve the fuel efficiency of off road vehicles. Journal of Terramechanics, 70, 2017, pp. 1-11.

[3] Barbosa L.A.P., Magalhaes P.S.G. Tire tread pattern design trigger on the stress distribution over rigid surfaces and soil compaction. Journal of Terramechanics, 58, 2015, pp. 27-38.

[4] Taghavifar H., Mardan, A. Evaluating the effect of tire parameters on required drawbar pull energy model using adaptive neuro-fuzzy inference system. Energy, 85, 2015, pp. 586-593.

[5] Moitzi G., Haas M., Wagentristl H., Boxberger J., Gronauer A. Energy consumption in cultivating and ploughing with traction improvement system and consideration of the rear furrow wheel-load in ploughing. Soil \& Tillage Research, 134, 2013, pp. 56-60.

[6] Eto R., Sakata K., Yamakawa J. Driving force distribution based on tyre energy for independent wheel-drive vehicle on rough ground. Journal of Terramechanics, 76, 2018, pp. 29-38.

[7] Damanauskas V., Janulevičius A. Differences in tractor performance parameters between singlewheel 4WD and dual-wheel 2WD driving systems. Journal of Terramechanics, 60, 2015, pp. 63-73.

[8] Zoz F.M. Predicting tractor field performance. Trans. ASAE 15, 1972, pp. 249-255.

[9] Battiato A., Diserens E. Influence of tyre inflation pressure and wheel load on the traction performance of a $65 \mathrm{~kW}$ MFWD tractor on a cohesive soil. Journal of Agricultural Science, 5(8), 2013, pp. 197-215.

[10] Lacour S., Burgun C., Perilhon C., Descombes G., Doyen V. A model to assess tractor operational efficiency from bench test data. Journal of Terramechanics, 54, 2014, pp. 1-18.

[11] Janulevičius A., Damanauskas V., Pupinis G., Effect of variations in front wheels driving lead on performance of a farm tractor with mechanical front-wheel-drive. Journal of Terramechanics, 77, 2018, pp. 23-30.

[12]Lee J.W., Kim, J.S., Kim K.U. Computer simulations to maximise fuel efficiency and work performace of agricultural tractors in rotovating and ploughing operations. Biosystems engineering, 142, 2016, pp. 1-11.

[13] Molari G., Bellentani L., Guarnieri A., Walker M., Sedoni E. Performance of an agricultural tractor fitted with rubber tracks. Biosystems engineering, 111, 2012, pp. 57-63.

[14] Lovarelli D., Bacenetti J., Fiala M. Effect of local conditions and machinery characteristics on the environmental impacts of primary soil tillage. Journal of Cleaner Production, 140, 2017, pp. 479491.

[15] Battiato A., Diserens E. Tractor traction performance simulation on differently textured soils and validation: A basic study to make traction and energy requirements accessible to the practice. Soil \& Tillage Research, 166, 2017, pp. 18-32.

[16] Kim J., Lee J. Traction-energy balancing adaptive control with slip optimization for wheeled robots on rough terrain. Cognitive Systems Research, 49, 2018, pp. 142-156.

[17] Maclaurin B. Using a modified version of the Magic Formula to describe the traction/slip relationships of tyres in soft cohesive soils. Journal of Terramechanics, 52, 2014, pp. 1-7.

[18]Brixius WW., Wismer R.D. Traction Prediction Equations for Wheeled vehicles. John Deere Report No. 109. Project 9, 1975. 
[19]Гинсбург Ю.В., Парфёнов А. П., Швед А.И. Тяговые характеристики гусеничных и колёсных промышленных тракторов. Выпуск 13.-М. ЦНИИТЭ тракторсельхозмаш, 1981.

[20] Damanauskas V., Janulevičius A., Pupinis G. Influence of extra weight and tire pressure on fuel consumption at normal tractor slippage. Journal of Agricultural Science, 7(2), 2015, pp. 55-67.

[21] Janulevičius A., Pupinis G., Lukštas J., Damanauskas V., Kurkauskas V. Dependencies of the lead of front driving wheels on different tire deformations for a MFWD tractor. Transport, 32(1), 2017, pp. 23-31.

[22] Kurkauskas V., Janulevičius A., Pupinis G. Influence of inflation pressure in tires on traction ratio $2 \mathrm{WD}$ and $4 \mathrm{WD}$ driving modes of tractor. Engineering for rural development: 15th international scientific conference proceedings, Vol. 15, 2016, pp. 448-455. 